\title{
Retrospective analysis of cases consulted at the department of psychiatry in a general hospital in Guangzhou, China
}

\author{
Zhang LL ${ }^{1 *}$ and Zhao JP2 \\ 'Department of Psychiatry, Guangzhou First People's Hospital, South China University of Technology, \\ Guangzhou, Guangdong, China \\ ${ }^{2}$ Department of Psychiatry and Mental Health Institute of the Second Xiangya Hospital, Central \\ South University, Chinese National Clinical Research Center on Mental Disorders, Chinese National \\ Technology Institute on Mental Disorders Hunan Key Laboratory of Psychiatry and Mental Health, \\ Changsha, Hunan, China
}

Received: 30 April, 2021

Accepted: 18 May, 2021

Published: 19 May, 2021

*Corresponding author: Zhang LL, Department of Psychiatry, Guangzhou First People's Hospital, the Second Affiliated Hospital of South China University of Technology, 1 Panfu Road, Guangzhou, Guangdong, China, Tel: +86 2081046473; E-mail: Ilzhang1304@126.com

Keywords: Consultation-liaison psychiatry; General hospital; Mental disorder; Anxiety

https://www.peertechzpublications.com

Check for updates

\begin{abstract}
Objective: To comprehensively analyze cases of psychiatric consultation in a general hospital and provide a primary reference for the development of consultationliaison psychiatry.

Method: A retrospective study was conducted by analyzing data collected over a two-year period regarding psychiatric consultations from the inpatient registry in a general hospital.

Results: A total of 926 and 774 psychiatric consultations were recorded in 2016 and 2017, respectively. The most common reason for consultation was unexplained somatic symptoms. Consultations based on psychological evaluation, and mental/behavioral disorders due to organic diseases and perioperative stress were significantly higher in 2017 than those in 2016 ( $P<0.01)$. Diagnoses of neurotic, stress-related and somatoform disorders were significantly lower in 2017 compared to those in 2016 (269 [34.8\%] cases in 2017 vs. 373 [ $40.3 \%$ ] cases in $2016 ; P=0.019$ ). Among specific diagnoses, generalized anxiety disorder was the most common.
\end{abstract}

Conclusion: Most patients with depressive or anxiety disorders visit a general hospital due to somatic symptoms. It is necessary to train non-psychiatrists to identify mental disorders efficiently, as well as to extend the comprehensive consultation model to include more clinical departments.

\section{Introduction}

Mental health problem is a serious issue among medically ill patients in general hospitals. Patients with mental disorder comorbidities show increased morbidity and mortality. If these comorbidities are not recognized and treated, they not only lead to an increased risk of multiple hospital visits and prolonged hospital stay, but also to higher medical expenses and ineffective treatment [1-3]. Due to the importance placed on mental health in China, the National Mental Health Work Plan (2015-2020) specifies that tertiary referral hospitals must include a psychiatric department. Huang, et al. conducted a questionnaire-based cross-sectional epidemiological study on the prevalence of mental disorders in China between 2013 and 2015, and reported that anxiety disorders were the most common class of disorders among subjects both in the twelve months preceding the interviews, and in their lifetime [4]. Approximately $50 \%$ of the patients with a major depressive disorder or anxiety disorder prefer to visit a general hospital for the first consultation. Furthermore, more than $80 \%$ of those patients complaint only about somatic symptoms [5]. Patients with chronic psychical illness, or those in the perioperative period, have increased risks of comorbidities such as anxiety or depression [6-8]. 
Psychiatric consultation-liaison services play an important role in the diagnosis and treatment of mental comorbidities and psychological burdens in patients [9]. However, this model cannot be implemented for all patients with mental health concerns because of the high prevalence of mental comorbidities. Moreover, the inability to identify cases of mental disorders, or misdiagnose them, in non-psychiatry departments is common, and eventually results in treatment delay and waste of medical resources [10]. Pezzia, et al. reported that evaluation of a known concern (such as substance use, affective disorder, or suicidal ideation) was the most common reason for psychiatric referral $(41.7 \%)$ in inpatient medical teams [11]. Currently, there are few reports regarding intra-hospital consultation of cases to psychiatry departments in general hospitals in China, and data regarding the working conditions in these departments are also insufficient. We examined all cases of consultations to psychiatrists in a tertiary referral hospital between 2016 and 2017, with the aim of classifying them using different criteria and providing a primary reference for the development of Consultation-Liaison Psychiatry (CLP) in China.

\section{Subjects and Methods}

\section{Ethics}

The study protocol was approved by the ethics committee of Guangzhou First People's Hospital. All patients provided written informed consent for their participation.

\section{Study design and participation}

Intra-hospital consultation was defined as a clinical department or medico-technical department (henceforth referred to as "principal department") consulting a psychiatrist or the psychiatry department within the same hospital (henceforth referred to as "consultant psychiatrist") to provide guidance regarding diagnosis and treatment of psychiatric disorders within the scope of their practice. Consultations that were accepted within 24 hours were considered in the study. Cases where the consultant psychiatrist arrived by the bed of the patient within 10 minutes of referral were classified as urgent consultations. Special cases were those that were referred directly to the chief of the psychiatry department for guidance.

We carried out this retrospective study by extracting information from the inpatient registry. New cases referred to the department of psychiatry in our hospital between 1 January 2016 and 31 December 2017 were included in the study. All consultation cases were registered in the patient record system. Repeated consultations for the same patient were not included in the study. Thus, we counted the total number of new consultation cases instead of the total number of visits to the department of psychiatry.

\section{Statistical analysis}

All statistical analyses were conducted using IBM SPSS software, version 22.0 (IBM Corp., Armonk, N.Y., USA). Twotailed statistical tests were conducted, with a $P$ value $<0.05$ considered as statistically significant. Continuous variables were described using summary statistics such as mean \pm Standard Deviation (SD), and their normality was assessed by the Shapiro-Wilk normality test. Categorical variables were described using frequencies and percentages. Data were compared using the $\mathrm{t}$-test or $\chi^{2}$ test as appropriate.

\section{Results}

\section{General information}

Between 1 January 2016 and 31 December 2017, 1700 new cases of intra-hospital psychiatric consultations were registered. The total number of inpatients, excluding repeated hospitalizations, over the same period were 53627 and 55249 in 2016 and 2017, respectively. Out of those inpatients, 926 $(1.7 \%)$ patients in 2016 , and $774(1.4 \%)$ patients in 2017 were referred for psychiatric consultation.

In 2016,355 out of the 926 patients $(38.3 \%)$ referred for psychiatric consultation were male and $571(61.7 \%)$ patients were female. The age range was 8-97 years with a mean of $62.72 \pm 18.21$ years. Further, $30(3.2 \%)$ cases were urgent consultations and $896(96.8 \%)$ were general consultations; A history of mental disorders was found in 365 (39.4\%) cases.

In 2017,294 out 774 patients $(38.0 \%)$ were male and 480 patients $(62.0 \%)$ were female. The age range was $8-95$ years with a mean of $61.16 \pm 18.27$ years. There were $22(2.8 \%)$ urgent consultations and $752(97.2 \%)$ general consultations. A history of mental disorders was found in 198 (25.6\%) cases, which was significantly lower than that seen in $2016(P<0.001)$ (Table 1). No significant differences were observed between the two groups for other variables $(P>0.05)$ (Table 1$)$.

\section{Distribution of "principal department"}

A total of 31 clinical departments had referred cases to the department of psychiatry for a consultation. Among these, the three "principal departments" which made the maximum number of referrals were the department of neurology (291 [31.4\%] in 2016, 187 [24.2\%] in 2017), the department of geriatrics (92 [9.9\%] in 2016, $92[11.9 \%]$ in 2017), and the department of gastroenterology $(57[6.2 \%]$ in $2016,83[10.7 \%]$ in 2017) (Table 2).

Table 1: Demographic data of psychiatric consultation cases between 2016 and 2017

\begin{tabular}{|c|c|c|c|c|}
\hline \multirow[t]{2}{*}{ Variable } & \multicolumn{2}{|c|}{ Psychiatric consultation cases } & \multicolumn{2}{|c|}{ Analysis } \\
\hline & $2016(n=926)$ & $2017(n=774)$ & & \\
\hline & \multicolumn{2}{|c|}{ Mean $\pm S D$} & t-score & $P$ \\
\hline \multirow[t]{2}{*}{ Age (years) } & $62.72 \pm 18.21$ & $61.16 \pm 18.27$ & 1.715 & 0.080 \\
\hline & \multicolumn{2}{|c|}{$n(\%)$} & $\chi^{2}$-statistic & $P$ \\
\hline \multicolumn{5}{|l|}{ Sex } \\
\hline Male & $355(38.3 \%)$ & $294(38.0 \%)$ & 0.022 & 0.882 \\
\hline Female & $571(61.7 \%)$ & $480(62.0 \%)$ & & \\
\hline History of mental disorders & $365(39.4 \%)$ & $198(25.6 \%)$ & 36.435 & 0.000 \\
\hline \multicolumn{5}{|l|}{ Consultation type } \\
\hline urgent consultation & $30(3.2 \%)$ & $22(2.8 \%)$ & 0.225 & 0.636 \\
\hline general consultation & $896(96.8 \%)$ & $752(97.2 \%)$ & & \\
\hline
\end{tabular}




\section{Reasons for consultation}

The most common reasons for consultation in both 2016 (926 cases) and 2017 (774 cases) were- unexplained somatic symptoms (admitted due to physical discomfort without any evidence of organic disease upon medical examination) (519 [56.0\%] in 2016, 372 [48.1\%] in 2017), history of mental disorders in patients who were admitted due to physical diseases (325 [35.1\%] in 2016, 188 [24.3\%] in 2017), and mental/behavioral disorders due to organic diseases (38 [4.4\%] in 2016, 98 [12.7\%] in 2017) (Table 3). Other reasons included psychological evaluation, and mental/behavioral disorders due to overuse of psychotropic drugs, perioperative stress, and acute stress events. Consultations due to psychological evaluation, and mental/behavioral disorders due to organic diseases, and perioperative stress showed a significant increase in 2017 than those in $2016(P<0.01)$. In contrast, consultations due to unexplained somatic symptoms, history of mental disorders in patients who were admitted due to physical diseases, and mental/behavioral disorders due to overuse of psychotropic drugs showed a significant decrease in 2017 than those in 2016 $(P<0.05)$ (Table 3).

\section{Classification of consultation diagnosis}

The top three diagnoses, made according to the criteria outlined in the "ICD-10 Classification of Mental and Behavioural Disorders," by consultant psychiatrists were as follows: 1 . neurotic, stress-related and somatoform disorders (373 out of 926 [40.3\%] in 2016, 269 out of 774 [34.8\%] in 2017), 2. $\operatorname{mood}$ disorders (207/926 [22.4\%] in 2016, 172/774 [22.2\%] in 2017), and 3. mental disorders due to brain damage and dysfunction, and physical disease (159/926 [17.2\%] in 2016, 99/774 [12.8\%] in 2017) (Table 4). Furthermore, among neurotic, stress-related and somatoform disorders, the distribution of specific disease diagnoses were as follows: generalized anxiety disorder (342 out of 373 [91.7\%] in 2016, 243 out of 269 [90.3\%] in 2017), somatoform disorder $(14 / 373$ [3.8\%] in 2016, 20/269 [7.4\%] in 2017), dissociative (conversion) disorder (10/373 [2.7\%] in 2016, 5/269 [1.9\% ] in 2017), and adjustment disorder (7/373 [1.8\% ] in 2016, 1/269 [0.4\%] in 2017). Among cases diagnosed as mood disorders, 204 out of 207 (98.5\%) and 170 out of 172 (98.3\%) consultations were made for depressive episodes in 2016 and 2017, respectively, and the rest were for bipolar disorder.

Table 2: Distribution of cases by "principal department" $[n(\%)]$.

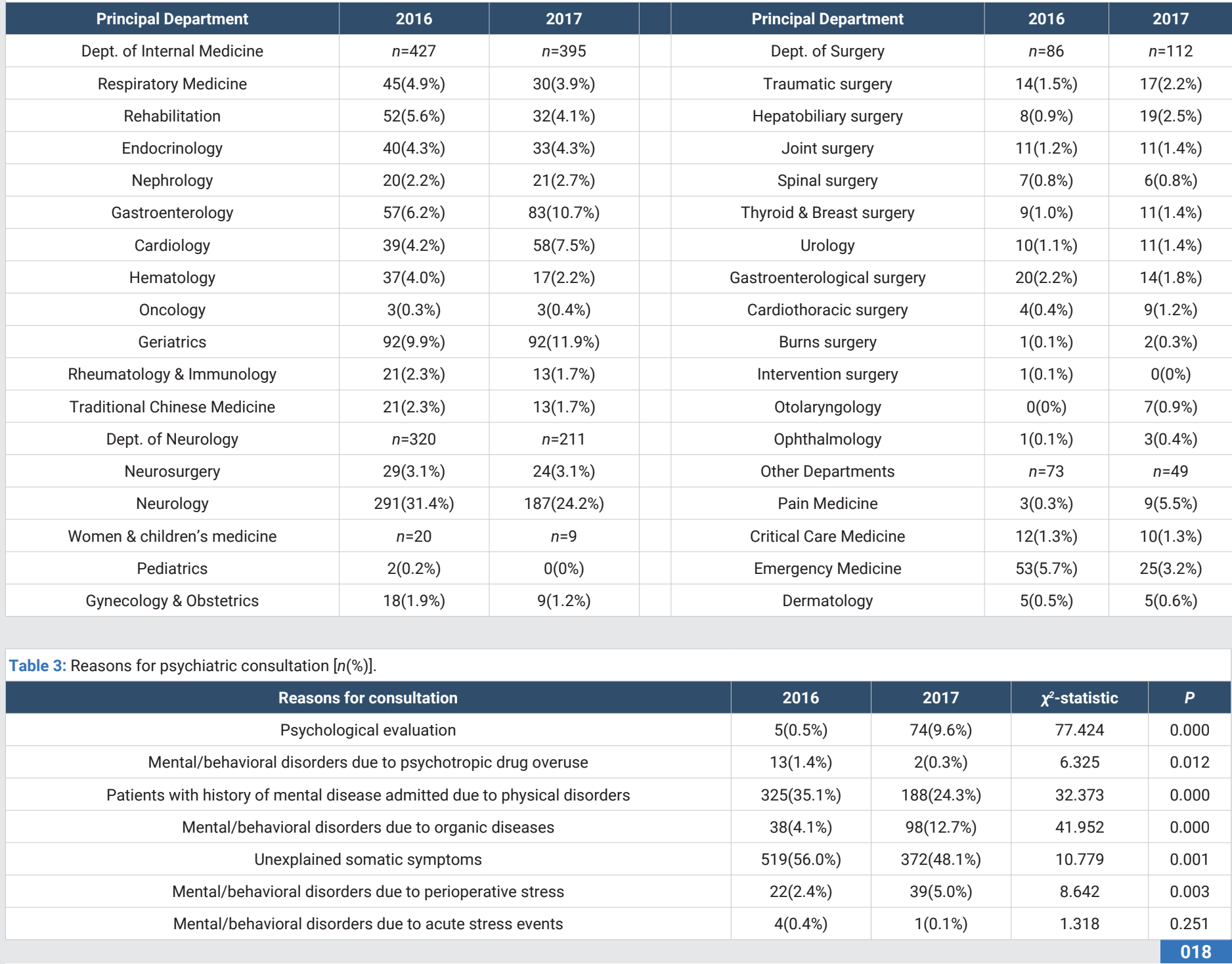

Citation: Zhang LL, Zhao JP (2021) Retrospective analysis of cases consulted at the department of psychiatry in a general hospital in Guangzhou, China. Arch Gerontol Geriatr Res 6(1): 016-021. DOI: http://dx.doi.org/10.17352/aggr.000029 
Table 4: Classification of psychiatric diagnosis [n(\%)].

\begin{tabular}{|c|c|c|c|c|}
\hline Diagnosis & 2016 & 2017 & $\chi^{2}$-statistic & $\boldsymbol{P}$ \\
\hline Disregard of mental and behavioral disorders & $65(7.0 \%)$ & $60(7.8 \%)$ & 0.332 & 0.564 \\
\hline Dementia & $45(4.9 \%)$ & $37(4.8 \%)$ & 0.006 & 0.939 \\
\hline Delirium & $9(1.0 \%)$ & $6(0.8 \%)$ & 0.187 & 0.666 \\
\hline Mental disorders due to brain damage and dysfunction and to physical disease & $159(17.2 \%)$ & $99(12.8 \%)$ & 6.283 & 0.012 \\
\hline Schizophrenia, schizotypal, and delusional disorders & $20(2.2 \%)$ & $19(2.5 \%)$ & 0.164 & 0.686 \\
\hline Mood disorders & $207(22.4 \%)$ & $172(22.2 \%)$ & 0.004 & 0.948 \\
\hline Neurotic, stress-related and somatoform disorders & $373(40.3 \%)$ & $269(34.8 \%)$ & 5.478 & 0.019 \\
\hline Behavioral syndromes associated with physiological disturbances and physical factors & $23(2.5 \%)$ & $25(3.2 \%)$ & 0.856 & 0.355 \\
\hline Disorders of adult personality and behavior & $2(0.2 \%)$ & $0(0 \%)$ & 1.674 & 0.196 \\
\hline Behavioral and emotional disorders with onset usually occurring in childhood and adolescence & $1(0.1 \%)$ & $0(0 \%)$ & 0.836 & 0.360 \\
\hline Acatalepsia & $11(1.2 \%)$ & $84(10.9 \%)$ & 74.643 & 0.000 \\
\hline Mental/behavioral disorders due to the use of psychoactive substances & $11(1.2 \%)$ & $2(0.3 \%)$ & 4.800 & 0.028 \\
\hline Mental retardation & $0(0 \%)$ & $1(0.1 \%)$ & 1.197 & 0.274 \\
\hline
\end{tabular}

Notably, cases that were diagnosed as mental disorders due to brain damage and dysfunction, and to physical disease, as well as those diagnosed as neurotic, stress-related and somatoform disorders showed a significant decrease in 2017 compared with those in $2016(P<0.05)$. Similarly, among reasons for consultation, cases of mental/behavioral disorders due to overuse of psychotropic drugs were significantly lower in 2017 than those in $2016(P=0.028)$ (Table 4).

\section{Discussion}

Substantial developments in the biopsychosocial-medical model have enabled improvements in the identification of mental diseases by non-psychiatrists. In addition, due to recent developments, particularly the increased use of new medical technology and psychiatric medications over the past decade, CLP has become an important part of psychiatry [12]. Although there have been some articles on CLP, our study is the first report in Guangzhou which focuses on the analysis of the changes in psychiatric consultation during the two years in a general hospital, with the aim to provide a primary reference for the development of consultation-liaison psychiatry. We found that somatic symptoms were the primary reason for patients with depressive disorder or anxiety disorder when visiting in a general hospital, which suggested that the ability of non-psychiatrist in general hospital to early identify mental disorders should be strengthened.

\section{Current status of CLP in general hospitals}

Roughly half of general hospital patients may have a psychiatric issue that impacts care, yet most of these are not recognized during hospital admission $[1,13,14]$. More than half of the cases of psychiatric comorbidities in patients are not recognized by the primary medical teams. [15] Ji, et al. analyzed domestic studies conducted in China and found that the rate of psychiatric consultations was between $0.02 \%$ and $3.60 \%$ [16]. Although the psychiatric consultation rate observed in our study was $1.4-1.7 \%$, it does not reflect the actual prevalence of mental disorders in the general population. He, et al. reported that the rate of incidence of depression or anxiety disorders recorded in fifteen tertiary care hospitals from five cities in China was $16.5 \%$. Li, et al. [10] found a rate of incidence of $14.27 \%$ for depression or anxiety disorders in cardiovascular outpatients from fourteen tertiary care hospitals in China [17]. In terms of the distribution of cases among "principal departments," non-surgical departments had the highest frequency, which was in line with previous reports from China $[18,19]$. The department of neurology made the highest number of consultations, accounting for close to one third of the cases in the two year-period of our study. This result was consistent with findings of other studies, suggesting that neurological diseases are strongly associated with mental disorders [20-22].

\section{Reasons for psychiatric consultation}

The most common reason for consultation was unexplained somatic symptoms, which accounted for $52.05 \%$ of the cases over the two-year period of this study. The second and third most common reasons are a history of mental disorders in patients admitted for physical disorders, and mental/behavioral disorders due to organic diseases, respectively. It was easier for non-psychiatrists to identify mental disorders when the patient met the abovementioned conditions. Furthermore, there was a significant increase in reasons for consultation like psychological evaluation, and mental/behavioral disorders due either to organic diseases or perioperative stress in 2017, compared to those in 2016. In contrast, there was a significant decrease in reasons for consultation like unexplained somatic symptoms, history of mental disorders in patients admitted due to physical disorders, and mental/behavioral disorders due to overuse of psychotropic drugs in 2017 compared with those in 2016. These changes may be due to greater attention being paid to mental health by both non-psychiatrists and patients. There was an increased need for psychological assessment in non-psychiatry departments, while the consultation of cases with a history of mental disorders had decreased significantly. Due to the improved ability of non-psychiatrists to accurately assess depression and anxiety in patients, and the use of psychotropic drugs by non-psychiatrists to treat them, the number of patients requiring psychiatric consultation had 
decreased. It is also noteworthy that acceptance of mental disorders by patients had improved. An increasing number of patients with unexplained somatic symptoms, or mental or behavioral disorders were willing to take the initiative to visit the outpatient department of psychiatry in the general hospital. The total number of outpatients visiting the psychiatry department in our hospital was 21850 in 2017, an increase of $20.63 \%$ over the previous year.

\section{Psychiatric consultation diagnosis}

If we consider the diagnosis, there were 585 and 374 cases diagnosed as generalized anxiety disorder or depression in 2016 and 2017, respectively. Together, they accounted for $56.41 \%$ of the total number of consultations. These results were consistent with those reported previously, both in China and worldwide, which indicates that somatic symptoms were the primary reason for a hospital visit among most of the patients with depressive disorder or anxiety disorder [10,23,24]. Recently, it has been observed that mild, rather than severe, mental disorder has become the most common type of psychiatric disease diagnosed upon consultation in general hospitals. In addition to the high rate of incidence of depressive or anxiety disorders, and the probability of those being comorbidities with physical disorders, our study also demonstrated that greater attention is being paid to psychological factors. This was not limited only to severe mental disorders, but was also observed for mild mental disorders $[10,19,23,25,26]$.

Most of inpatients who had mental disorders in general hospitals were underdiagnosed. This means that without systematic screening by psychiatrists, the mental healthcare needs of many patients could go unmet, or scarce resources could be misallocated. Along with developments in CLP in the past decade, psychiatric consultations in general hospitals have also increased. Possible reasons for this could be: 1 . increased knowledge and awareness regarding mental illness among non-psychiatrists, which has increased the rate of identification of mental illness; 2 . the stressful nature of the job and patient-physician relationship, which encourages physicians practicing strictly within the scope allowed under law to seek professional help for looking after their own mental health; 3. intense social competition resulting in increased stress that has led to a rise in the rate of incidence of mental disorders. Moreover, due to an aging population, there is an increase in cases of neurological and mental disorders due to cardiovascular and cerebrovascular diseases, senile dementia, and metabolic disorders; 4 . due to the stigma associated with mental disorders, patients often refuse to visit a psychiatrist, but prefer to visit a general physician instead for somatic symptoms or follow-up of previously treated physical disorders. Thus, in order to decrease the rate of underdiagnoses or misdiagnoses of mental disorders, it is important to train clinicians in nonpsychiatry departments to identify and treat mental disorders, especially by recognizing the somatic manifestations of mental disorders. Moreover, multidisciplinary teams (MDTs) are effective in strengthening cooperation between psychiatric and non-psychiatric departments $[27,28]$. Hong, et al. compared the effects of different modes of liaison psychiatric service and found that a combination of comprehensive assessment, psychiatric consultation and interdisciplinary teamwork was very efficient in reducing the duration of hospital stay and medical expenses [29]. This proactive and comprehensive consultation model is worthy of being promoted in general hospitals in order to improve the diagnostic accuracy of nonpsychiatric doctors and encourage patient compliance with recommendations of psychiatric consultation [30,31].

\section{Limitations}

Our study was subject to a few limitations. First, consultation diagnosis was based on a clinical interview by psychiatrists without using a structured clinical interview questionnaire. Second, consultation data retrieved from one of the hospitals had certain geographical limitations. Third, our study did not account for follow-ups and recovery rates, and did not evaluate the risk of patient suicide. Continuation of CLP services will benefit the overall wellbeing of patients [32]. Although a preliminary analysis of all consultations was conducted in the study, we did not focus on a particular disorder. Future studies that focus on the progression of a specific physical disease with depressive or anxiety comorbidities and explore the impact of mental illness on the outcome of the physical disease are required. Fourth, our study analyzed the two-year CLP data in 2016 and 2017, which may not reflect sufficient outcome. We plan to conduct further follow-up of CLP, such as detailed analysis of consultation data within 5 years.

\section{Conclusion}

We found that there was a considerable need for consultations with the psychiatry department in the general hospital. The primary reason for psychiatric consultations was unexplained somatic symptoms that are clinical manifestations of depressive or anxiety disorders. It is important to encourage psychiatric consultation, and train clinicians from nonpsychiatry departments to identify somatic manifestations of mental disorders with greater efficiency, as well as to extend psychiatric services to tertiary healthcare centers and other healthcare services.

\section{Funding}

This study was supported by grants from the Science and Technology Program of Guangzhou (Grant No. 202002030262) and the Natural Science Foundation of Guangdong Province (Grant No. 2017A030313809).

\section{References}

1. Desan PH, Zimbrean PC, Weinstein AJ, Bozzo JE, Sledge WH (2011) Proactive psychiatric consultation services reduce length of stay for admissions to an inpatient medical team. Psychosomatics 52: 513-520. Link: https://bit.ly/3v38Xv0

2. Oldham MA, Chahal K, Lee HB (2019) A systematic review of proactive psych atric consultation on hospital length of stay. Gen Hosp Psychiatry 60: 120-126. Link: https://bit.ly/3byc2w0

3. Jeeva F, Dickens C, Coventry P, Bundy C, Davies L (2013) Is treatment of depression cost-effective in people with diabetes? A systematic review of the economic evidence. Int J Technol Assess Health Care 29: 384-391. Link: https://bit.ly/3ytfLVR 
4. Huang Y, Wang Y, Wang H, Liu Z, Yu X, et al. (2019) Prevalence of mental disorders in China: a cross-sectional epidemiological study. Lancet Psychiatry 6: 211-224. Link: https://bit.ly/3uWKgRC

5. Zeng QZ, He YL, Liu ZN (2012) Distribution of physical symptoms and diagnoses in patients with depression or anxiety disorder in general hospital. Chin Gen Prac 15: 2656-2661.

6. Ahn HJ, Shin MK, Seo JK, Jeong SJ, Cho AR, et al. (2019) Cross-sectional study of psychiatric comorbidities in patients with atopic dermatitis and nonatopic eczema, urticaria, and psoriasis. Neuropsychiatr Dis Treat 15: 1469-1478. Link: https://bit.ly/3uZCVkb

7. Szász JA, Orbán-Kis K, Constantin VA, Péter C, Bíró I, et al. (2019) Therapeutic strategies in the early stages of Parkinson's disease: a cross-sectional evaluation of 15 years' experience with a large cohort of Romanian patients. Neuropsychiatr Dis Treat 15: 831-838. Link: https://bit.ly/3eX51Y0

8. Jarzemski P, Brzoszczyk B, Popiołek A, Stachowicz-Karpińska A, Gołota S, et al. (2019) Cognitive function, depression, and anxiety in patients undergoing radical prostatectomy with and without adjuvant treatment. Neuropsychiatr Dis Treat 15: 819-829. Link: https://bit.ly/3ose7yV

9. Stein B, Müller MM, Meyer LK, Söllner W (2020) Psychiatric and Psychosomatic Consultation-Liaison Services in General Hospitals: A Systematic Review andMeta-Analysis of Effects on Symptoms of Depression and Anxiety Psychother Psychosom 89: 6-16. Link: https://bit.ly/3wfXIAI

10. He YL, Ma H, Zhang L, Liu ZN, Jia FJ, et al. (2009) A cross-sectional survey of the prevalence of depressive-anxiety disorders among general hospital outpatients in five cities in China. Chin $\mathrm{J}$ Intern Med 48: 748-751. Link: https://bit.ly/33SDRLp

11. Pezzia C, Pugh JA Lanham HJ, Leykum LK (2018) Psychiatric consultation requests by inpatient medical teams: an observational study. BMC Health Serv Res 18: 336. Link: https://bit.ly/3yeoz1D

12. Ferrari S, Mattei G, Marchi M, Galeazzi GM, Pingani L (2020) Is ConsultationLiaison Psychiatry 'Getting Old'? How Psychiatry Referrals in the General Hospital Have Changed over 20 Years. Int J Environ Res Public Health 17: 7389. Link: https://bit.ly/3oqcxxz

13. Oldham MA, Chahal K, Lee HB (2019) A systematic review of proactive psychiatric consultation on hospital length of stay. Gen Hosp Psychiatry 60: 120-126. Link: https://bit.ly/3byc2w0

14. Finn CT, Thakur D, Shea KM, Riblet NBV, Lee HB, et al. (2018) Electronic Medical Record Reporting Enhances Proactive Psychiatric Consultation. Psychosomatics 59: 561-566. Link: https://bit.ly/3tVLj2X

15. Sledge WH, Gueorguieva R, Desan P, Bozzo JE, Dorset J, et al. (2015) Multidisciplinary Proactive Psychiatric Consultation Service: Impact on Length of Stay for Medical Inpatients. Psychother Psychosom 84: 208-216. Link: https://bit.ly/33SEaWz

16. Ji J, Ye C (2012) Consultation-liaison psychiatry in China. Shanghai Arch Psychiatry 24: 124-130. Link: https://bit.ly/3bycFFS

17. Li G, Jiang R, Guo C, Liu M, Zhang L (2014) Prevalence of depressive and anxiety disorders in cardiovascular outpatients from 14 tertiary general hospitals of 5 Chinese cities. Zhonghua Xin Xue Guan Bing Za Zhi 42: 1035 1038. Link: https://bit.ly/2Rt7Yq3
18. Wang HM, Shi W (2012) The analysis of 327 inter hospital psychiatric consultation patients in general hospital. Sichuan Medical Journal 33: 91-93.

19. Ye FY, Wang LJ, Zhong YL, Xu J, Huang QM (2014) Analysis of patient characteristics in each department of psychiatric consultation in general hospital. Journal of Neuroscience and Mental Health 14: 178-181.

20. Liu HL, Liu Y (2013) An analysis of 168 old inpatients with consulation-liasion psychiatry in a general hospital. Sichuan Mental Health 26: 248-250.

21. Sun XY, Tang CX, Lu QY (2009) Consultation liaison psychiatry for elderly patients in general hospital: Analysis of 131 cases. Journal of Psychiatry 22: 5-7. Link: https://bit.ly/3w8VMJQ

22. Lee CH, Kim DH, Moon YS (2019) Differential associations between depression and cognitive function in $\mathrm{MCl}$ and $\mathrm{AD}$ : a cross-sectional study. Int Psychogeriatr 30: 1-8. Link: https://bit.ly/3yoduv4

23. Marchi M, Magarini FM, Mattei G, Pingani L, Moscara M, et al. (2021) Diagnostic Agreement between Physicians and a Consultation-Liaison Psychiatry Team at a General Hospital: An Exploratory Study across 20 Years of Referrals. Int $J$ Environ Res Public Health 18: 749. Link: https://bit.ly/3hzu4IF

24. Zhou C, Rajaratnam T, Abbey S, Hawa R, Sheehan K, et al. (2018) Measuring quality of care in consultation liaison psychiatry: Outcomes from two Canadian hospitals. Gen Hosp Psychiatry 54: 54-56. Link: Link: https://bit.ly/3eWyQb7

25. Wood R, Wand AP (2014) The effectiveness of consultation-liaison psychiatry in the general hospital setting: a systematic review. J Psychosom Res 76:175 192. Link: https://bit.ly/3hHaVOq

26. Guo HR, Li YH (2008) Clinical practice of consultation-liaison psychiatry in general hospital. Chinese Journal of Practice Nervous Disease 1: 46-48.

27. Mattinson AR, Cheeseman SJ (2018) Development and implementation of a structured ward round in acute adult psychiatry. BMJ Open Qual 7 e000035. Link: https://bit.ly/3tWL1ZQ

28. Bagraith KS, Strong J, Meredith PJ, McPhail SM (2018) What do clinicians consider when assessing chronic low back pain? A content analysis of multidisciplinary pain centre team assessments of functioning, disability, and health. Pain 159: 2128-2136. Link: https://bit.ly/3eYf13i

29. Hong X, Wei J, Zhao XH, Liu XH, Shi LL, et al. (2016) Retrospective Analysis of Liaison Psychiatric Service in Elderly Inpatients in A General Hospital. Zhongguo Yi Xue Ke Xue Yuan Xue Bao 38: 422-427. Link: https://bit.ly/2RY7NDb

30. Nogueira V, Lagarto L, Cerejeira J, Renca S, Firmino H (2013) Improving quality of care: focus on liaison old age psychiatry. Ment Health Fam Med 10: 153158. Link: https://bit.ly/2Qva74g

31. Oldham MA, Chahal K, Lee HB (2019) A systematic review of proactive psychiatric consultation on hospital length of stay. Gen Hosp Psychiatry 60 120-126. Link: https://bit.ly/3byc2w0

32. De Giorgio G, Quartesan R, Sciarma T, Giulietti M, Piazzoli A, et al. (2015) Consultation-Liaison Psychiatry-from theory to clinical practice: an observational study in a general hospital. BMC Res Notes 24: 475. Link: https://bit.ly/3u0vSGG

Copyright: @ 2021 Zhang LL, et al. This is an open-access article distributed under the terms of the Creative Commons Attribution License, which permits unrestricted use, distribution, and reproduction in any medium, provided the original author and source are credited. 